\title{
The valuation high ground
}

\author{
Jeffrey J Stewart \& Ben Bonifant \\ Holding the valuation high ground allows a biotech company to get the most value from potential partners. Here is \\ how to establish and defend financial valuation.
}

\begin{abstract}
The 'high ground' in warfare is a position of offensive flexibility and defensive strength. Likewise, if you are a biotech company, you will want to hold the high ground in negotiations with potential partners. It is not enough simply to assert that your product has a high valuation. You must be able to defend that valuation. The stronger your defense, the more likely you will control the discussion.

We have recently conducted a survey of business development practices in pharmaceutical and biotech companies (Box 1). Here, we use the results to supplement our experience with the business development teams of major pharmaceutical companies and walk through the process of establishing and defending a favorable valuation.
\end{abstract}

\section{Estimating net present value}

The first step in holding the valuation high ground is to know where the battle will be fought. That is, you must select the high ground based on the valuation methodology used by the potential partner. In our recent survey, we asked which valuation methods are being used: licensing professionals indicated that net present value (NPV) and risk-adjusted NPV (rNPV) are the valuation methods most used by their companies. In fact, every in-licensing respondent in companies with revenue greater than $\$ 1$ billion answered that they use at least one of these methods. When only a single valuation method is used, the reliance on rNPV is pronounced (Supplementary Fig. 1).

NPV is simply the cash flow at each point in time discounted back to the present. There are three inputs for NPV: revenue, costs and the discount rate.

Jeffrey J. Stewart and Ben Bonifant are part of the business development practice at Campbell Alliance, Raleigh, North Carolina, USA. e-mail:bbonifant@campbell.com
Revenue. Estimate the revenue your product is expected to return if it reaches the market, using epidemiology, adoption (based on diagnosis, treatment and compliance) and price to back up your estimation.

A strong valuation is built on credible epidemiology. You need to be able to defend the claim that the population considered is the actual patient group that will be targeted for treatment, so don't include patients with mild and moderate disease if your treatment targets patients with severe disease. If you're speaking to patient organizations, remember that their motivations must be considered. For example, patient advocacy groups have the natural incentive to promote high-prevalence estimates. Likewise, drawing information from other manufacturers is potentially problematic, as some might project a large patient pool to bolster value or carefully define the indication so it has less than 200,000 patients in the United States in hopes of obtaining orphan drug status with the US Food and Drug Administration (Rockville, Maryland).

In addition, no disease has $100 \%$ presentation or diagnosis; no drug has $100 \%$ treatment rates, compliance or persistence; and no patient population will pay for $100 \%$ of drugs prescribed. If you choose to include $100 \%$ values for these parameters, you will lose both credibility and control of the negotiation. Instead, you should be ready to present values derived from secondary research or primary interviews with physicians for each of these values.

Apart from epidemiology and adoption, a strong valuation also reflects a nuanced understanding of the complex series of payments and product flows in a pharmaceutical supply chain. The price we care about is the revenue received by the manufacturer after the discounts are applied and rebates paid. In the pharmaceutical industry, this means

\section{Box 1 Our survey}

Our Dealmakers' Intentions Survey, conducted in February and March of 2009, drew 94 respondents across the spectrum of business development professionals. Of the respondents, 35\% were from development-stage companies, $33 \%$ from commercial companies with less than $\$ 1$ billion in revenue and 31\% from companies with more than $\$ 1$ billion in revenue. One respondent declined to answer. Questions were asked concerning dealmaking expectations and intentions, business development organization, deal characteristics and valuation.

reflecting wholesaler and retailer margins. It also means anticipating contracting strategies with payers and reflecting the anticipated program support or rebates in the valuation. As an out-licensor, you will seldom lose credibility by being ambitious, but you will lose the high ground if it becomes clear you do not understand the complexities of pharmaceutical reimbursement. If your product will enter either a highly competitive or managed category, interview payers to support your assumptions about pricing and reimbursement.

Also, a strong valuation reflects realistic expectations about the competitive environment. There are many uncertainties in a valuation that may stretch for 15-20 years. That said, the biotech/pharmaceutical industry is the most transparent on the planet. Product launches are anticipated years in advance, generic threats are timed to the day and even reformulations or delivery innovations are easily identified in regulatory databases. If you're out-licensing, you should own the discussion of how your product will fit in this emerging landscape. 


\section{Box 2 Talking to VCs}

The venture capital (VC) community relies on comparable analysis more than the biotech industry does, which means you might need to prepare a comparable analysis instead of a risk-adjusted net present value (rNPV) analysis. Remember that VCs are only interested in what your company is going to be worth when they can sell an equity stake, and there is no straightforward relationship between the rNPV of your asset and the liquidity value of the company.

The first step is to ask around the industry to see what sort of pre-money valuations are out there. This will help set the market rate for a company at your stage of development and will influence what the market will pay for your stock.

Then begin seeking comparables_-in other words, companies that have achieved a liquidity event recently (acquisition or initial public offering). The closer you match the comparables (for example, therapeutic area and estimated stage of development at liquidity) to where your project hopes to be at liquidity, the more credible the comparable analysis.

Here's an example: let us say the going pre-money valuation is $\$ 10$ million for series A investment, and the liquidity value is about $\$ 300$ million after 5 years by comparable analysis. For your company, let's estimate the cash needed to reach liquidity as $\$ 75$ million. (You should plan on using only half of the money invested in each round before seeking another: you will need 'runway' capital to remain credible-meaning you will spend about $\$ 37.5$ million of VC money.) We'll assume the investment rounds will be $\$ 10$ million, $\$ 20$ million and $\$ 45$ million.

You can then calculate the VC's internal rate of return (IRR) on its initial investment. IRR is $k$, where the initial investment equals the time-discounted payout. $\$ 10$ million = $\$ 37.5$ million $(1+k)^{-5}$. Solving for $k$ gives you $30 \%$.

Hold on to that number while you calculate the VC's 'cash-on-cash' return, which is simply the liquidity value divided by the investment. In this case, the cash-on-cash return is $\$ 37.5$ million / $\$ 10$ million $=3.75 \times$.

All of this allows you to stand in front of your venture capitalist and say, "You are looking at a $3.75 \times$ return in 5 years on a $\$ 10$ million investment, for a $30 \%$ IRR."

We often see negotiators argue over 'peak revenue' numbers that are widely different. To close the gap, we recommend explaining the drivers you considered when formulating your numbers. An out-licensor who is able to support his or her assumptions at each of the steps listed above will retain the valuation high ground. An inability to support any one assumption may lead potential partners to conclude that the market analysis is pure positioning and may cause them to dismiss the entire analysis. Even worse, a poorly defended market analysis for revenue can lead in-licensors to look more skeptically at the entire opportunity.

When dealing with venture capitalists, it's a whole different ball game (Box 2).

Costs. Developing a drug is costly and the timeline is lengthy. You must remember that as an out-licensor. By incorporating reasonable estimates for these investments, you can drive the negotiation toward cost-effective alternatives and avoid ceding the control of these important components of valuation to your partner. These costs can be divided into three categories.

Firstly, there are development costs. We've seen some presentations in which the revenue forecast is presented as a single number, as if there were perfect certainty of how the product would be taken up in the market, whereas the phase III trial costs are left to the partner's imagination because the presenter just doesn't have the experience to develop those estimates.

That isn't good enough. At the very least, estimate clinical trial costs based on what's been seen for similar products. Researchers who are not familiar with clinical trial costs can turn to observations for subject numbers in earlier studies and then multiply those numbers by estimates for the cost per subject. Per-subject costs currently average about $\$ 15,000-\$ 20,000$ for phase I or phase II trials and about $\$ 20,000-\$ 40,000$ for phase III (ref. 1). Be aware, however, that average persubject costs and development times vary by therapeutic area ${ }^{2}$. Clinical costs will certainly be based on the number and complexity of procedures required for each patient.

Secondly, there are commercial costs. Pharmaceutical products do not sell themselves, so include in your valuation the costs of the sales force, marketing and distribution. A primary care sales force in the United States often has 500 representatives.
Consider that the all-in costs often exceed $\$ 200,000$ per representative and you quickly reach an annual field force investment of $\$ 100$ million. Although those representatives may sell multiple products (usually, no more than three), you can be sure they will be focused on their lead product during its launch. In specialty areas the field force may be more like 100 representatives, but even there the annual costs would be more than $\$ 20$ million. To help understand these costs, you should research the number of physicians who will be responsible for prescribing the product, estimate how often a sales representative would need to visit them and then compare the result to the number of sales calls a representative might make in a single day. If all else fails, test the ratio of prescribing physicians to sales representatives-often this ratio is close to $100: 1$. Another trick is to compare the overall revenue for the product to the number of or cost of the representatives. It is not impossible to achieve revenue productivity above $\$ 1.5$ million per representative, but if your valuation suggests such performance you will probably need to explain why you expect to exceed industry benchmarks for sales productivity.

Marketing costs should also be estimated to start before launch, peak during the launch year and continue at some level throughout the revenue period. In our experience, if specific estimates are not available, a firstapproximation estimate of at least $10 \%$ of peak revenue annually spent on the combination of sales and marketing is needed for your valuation to be considered credible.

Thirdly, there are manufacturing costs. Costs for materials used in clinical development are likely to be extraordinarily high because they are being produced in low volumes and production techniques are just being worked out. Moreover, many of today's products rely on innovative technologies for which the cost of production is a low priority. In these cases, it often makes sense to simply assume gross margins (the difference between revenue and manufacturing costs) will be in line with comparable products currently in the market.

Discount rate. To calculate NPV, you will also need a discount rate (interest rate). Each cash flow (revenue minus cost) is discounted for time by multiplying by $(1+k)^{-n}$, where $k$ is the discount rate and $n$ is the number of years in the future the cash flow is projected to be realized. A lower discount rate yields a higher valuation, so it is often to your benefit as an out-licensor to use the discount rate appropriate for your partner: in our survey 


\section{Box 3 Calculating discount rate}

Risk-adjusted net present value (rNPV) - as the name implies_includes risks already subsumed in the net present value (NPV) discount rate. NPV's discount rate consists of two pieces: the time value of money and a risk premium. The time value of money is simply the risk-free rate of return, often estimated to be the return on a US Treasury security with a matched investment horizon. The risk premium includes all the risks faced by the company, including management risk, exchange-rate risk, market risk, country risk, legal risk, manufacturing risk, labor risk and clinical trial risk. If clinical trial risk is accounted separately (as in rNPV), then the appropriate discount rate for rNPV must be lower than that of the corresponding NPV. A reasonable estimate for an equity risk premium for the industry may be on the order of 5.5\%-6.5\% (a typical equity risk premium $)^{5}$ when clinical trial risks are accounted separately. This equity risk premium is then added to the risk-free rate of return (currently 3.8\% for the 20-year Treasury bond) to estimate the total discount rate for rNPV. In this example, the average industry rNPV discount should be about $9.3 \%-10.3 \%$. A company with risks that are higher or lower than the average industry risks should then be accounted correspondingly higher or lower discount rates. In most portfolio analysis, this is done by multiplying the systematic market risk, $\beta$, by the equity risk premium. of licensing executives, we found that large in-licensors tend to use a discount rate that is $2 \%$ lower than that used by precommercial companies (Supplementary Fig. 2).

With revenue, costs and discount rate (Box 3), you have all the factors you need to estimate NPV. NPV is simply the summation of all the cash flows discounted to the present.

\section{Estimating risk-adjusted NPV}

Risk-adjusted NPV is calculated by adjusting for clinical trial risks ${ }^{3}$. For example, if you are in a phase II trial, there are slightly better than even odds of reaching phase III. If the phase II trial fails, the money anticipated for phase III trials will never be spent. In this case, the costs of phase III trials-and all of the future revenue and costs-should be adjusted down by about $50 \%$ in rNPV.

Whenever possible, risk estimates should be based on experience from the relevant therapeutic area. Some therapeutic areas (for example, oncology) have lower clinical success rates than do other areas (for example, anti-infectives) $)^{4}$.

The discount rate used in rNPV should be lower than that used in NPV (Box 3).

\section{Allocation of value}

After completing the valuation and obtaining an rNPV (or a range of values), the next step is to determine how that value will be shared between parties in an alliance. That's usually defined through up-front payments, milestones and royalties (Box 4). How much of the value each party receives is typically based on the specific capabilities each party contributes to the alliance, the scarcity of those capabilities and the degree of risk borne by each party.
Each partner is entering the agreement because each expects to gain more value from their share of a partnership than could be obtained by pursuing the opportunity independently. As an out-licensor, you might wonder if you should keep the product to yourself, but inexperienced companies have a decidedly mixed record in successfully registering and launching products into unfamiliar commercial markets.

Whoever bears risk wants to be paid for it. Thus, the allocation of value should also reflect the risks that will be borne by each partner. Clinical trial risks are reasonably calculable, but these are not the only risks a biotech product faces. It is as important to recognize which party bears responsibility for the commercial risks. In recent years, many companies have experienced interruptions to previously reliable cash flow as a result of such events as the emergence of unforeseen adverse events, regulatory holds on manufacturing and surprisingly aggressive marketing investment by competitors. The partner who bears commercial risks will expect them to be reflected in its share of the expected value.

For a phase II compound, our observations of industry benchmarks indicate that value allocation to an out-licensor for a product with $50 \%$ probability of launch is in the $40 \%-60 \%$ range. The out-licensor who does not recognize the value provided by the partner loses the valuation high ground. If the out-licensor sees little value provided by the later development and commercialization activities of the partner, then there is little motivation to make a deal. Instead, as an out-licensor, you should strive to develop deal terms that assign the upside value to the capabilities contributed and risks borne by the potential partner.

\section{Conclusions-where you can negotiate on value}

In negotiations, it is critical to capture and defend the valuation high ground. This is true in large part because the unequal discount rates between in- and out-licensors tend to lead to deals that are highly front loaded (high up-front payments). The more

\section{Box 4 Show me the money}

There are several ways in which a deal can be structured. These are outlined below.

Up-front payment. This is an initial payment for compound rights. It is typically tied to the risk-adjusted value of the asset at the time of the deal, as the in-licensor is bearing risks of no or low success at that time. The out-licensor, though, secures at least some guaranteed return through an up-front payment.

Milestone payments. These are made to an out-licensor upon achievement of certain development or commercialization goals. Milestone payments reward the out-licensor for bearing and surpassing certain risks while protecting the in-licensor from having to take on all of the later risk of the product's development success and commercial performance. Typical milestones may include completion of phase II or III development, manufacturing success, US Food and Drug Administration approval or the achievement of preset market performance thresholds. As milestone payments are negotiated at the time of the deal, they are typically tied to the risk-adjusted value of the asset at the time of the deal.

Royalty payments. These are based on the product's market performance and are typically structured as a series of sales thresholds at which various royalty rates kick in. In a manner similar to milestone payments, royalty payments allow an in-licensor to manage risk while rewarding an out-licensor with a larger upside for the compound's successful market performance once pre- and post-commercialization risks have been eliminated. 
front loaded the deal, the more valuation matters and the more you must hold the valuation high ground. Every dollar in valuation may be another dollar coming to your company.

Given the importance of getting the best deal possible, it might seem natural to suggest that the out-licensor present only the most optimistic valuation scenarios. Some might even suggest that out-licensors leave valuation in the hands of their potential partners, perhaps allowing an auction process to yield the most attractive value to the company. This may be enticing, but the approach is impractical. No one knows as much about your asset as you do. You are in the best position to substantiate that value. Moreover, in-licensors and acquirers are becoming increasingly demanding of innovators to describe how the opportunity fits with their commercial strategy.

You have the opportunity to set the stage for potential partners. You can signal which markets are relevant and what it will take to complete development and undertake commercialization. The advice prepared in this discussion has focused on maximizing that opportunity. So long as you retain credibility and hold on to the valuation high ground, you will own the discussion. More importantly, you will establish yourself as a credible partner as you and your licensee begin taking on all of the challenges that emerge after the negotiation is completed.

1. Anonymous in Parexel's Bio/Pharmaceutical R\&D Statistical Sourcebook 2007/2008 Section 3, 118 (Parexel, Waltham, Massachusetts, 2007).

2. Anonymous in Parexel's Bio/Pharmaceutical R\&D Statistical Sourcebook 2006/2007 179 (Parexel, Waltham, Massachusetts, 2006)

3. Stewart, J.J., Allison, P.N. \& Johnson, R.S. Nat. Biotechnol. 19, 813-817 (2001).

4. Kola, I. \& Landis, J. Nat. Rev. Drug Discov. 3, 711715 (2004).

5. Goetzmann, W. \& Ibbotson, R. The Equity Risk Premium: Essays and Explorations. (Oxford Univ. Press, Oxford, 2006).
To discuss the contents of this article, join the Bioentrepreneur forum on Nature Network: http://network.nature.com/groups/bioentrepreneur/forum/topics 